\title{
Better Health Information Exploration
}

\author{
Patrick Cheong-Iao Pang ${ }^{1,3}$ Shanton Chang ${ }^{1}$ \\ mail@patrickpang.net_shanton.chang@unimelb.edu.au \\ Karin Verspoor ${ }^{1,2} \quad$ Jon Pearce $^{1}$ \\ karin.verspoor@unimelb.edu.au j.pearce@unimelb.edu.au \\ ${ }^{1}$ Department of Computing and ${ }^{2}$ Health and Biomedical \\ Information Systems \\ Informatics Centre \\ The University of Melbourne The University of Melbourne \\ ${ }^{3}$ National ICT Australia (NICTA) \\ Victoria Research Laboratory
}

This is the author's version of a work that was accepted for publication.

Changes resulting from the publishing process, such as peer review, editing, corrections, structural formatting, and other quality control mechanisms may not be reflected in this document. Changes may have been made to this work since it was submitted for publication.

The author acknowledges that the copyright of the final version is owned by the publisher. The final version can be accessed with the following link:

DOI: http://dx.doi.org/10.1145/2846439.2846444

\begin{abstract}
The provision of health information has to be clear and appealing to users. Research has shown that health

information seekers do not all have the same attributes, skills or needs. In any given health-related app or website, there is a need to provide tools for accessing information in ways that appeal to users. This is not always supported by current web technologies. As such, based on prior research on health information seeking behaviour and needs, we designed and created a proofof-concept website named Better Health Explorer to experiment on health information seekers. The pilot results show a positive effect on supporting and improving the experience of seekers with exploratory search behaviour.
\end{abstract}

\section{Author Keywords}

Exploratory search, health information seeking behaviour, information exploration

\section{ACM Classification Keywords}

H.5.2. User Interfaces: Evaluation/methodology

\section{Introduction}

Health websites increasingly provide convenient and genuine health information to the public. However, studies have shown that general users have different attributes, skills and needs in finding such information, and this diversity is not properly supported. Therefore, people experience frustration in accessing health 
information, leading to health messages not being conveyed as effectively as health information providers expect. To rectify this problem, we designed and implemented a prototype website called Better Health Explorer (BHX), for supporting various needs demonstrated in health information seeking processes.

We evaluated the prototype and present some preliminary results of that evaluation in this paper. A traditional health website was included in the test as a baseline. We found that the performance of participants did not degrade with BHX, while BHX provided more diverse and useful information to users in the search process. Overall, the early results show that the prototype is heading in the right direction to support and enhance health information seeking.

\section{Related Work}

Health Information Seeking Behaviour

Research has been conducted to investigate the motivations behind health information seeking behaviour (HISB). Wilson suggests that people will search for health information when feeling stressed and threatened when health problems are discovered [17, $18,19]$. In addition, curiosity and the eagerness to learn new knowledge are common catalysts for seeking health information $[4,18]$. External events (such as hearing about the health problems of a celebrity from media) can also trigger health information seeking [1].

\section{Exploratory Search}

Exploratory search often occurs when seekers are unfamiliar with the knowledge domain of the search topic, or unsure of how to approach the search topic [15]. Similarly, some instances of health information seeking behaviour can be identified as exploratory search, depending on the scenarios faced by seekers and their knowledge level of the health problem [10]. Exploratory search includes components of learning and investigation in addition to looking up information [9]. This exploratory search approach demonstrates different information seeking behaviour. For example, it involves a number of queries across a larger information space. Its counterpart, focused search, is often associated with more specific search goals. In this regard, we argue that a dedicated design is needed to cater for the needs of health information seeking and the characteristics of exploratory search.

\section{Problems and Challenges}

Search engines are the primary tools for people seeking health information $[6,13]$. However, studies have shown that keyword search is a barrier for many users. For instance, the general public normally have insufficient knowledge to describe health problems with appropriate keywords $[5,7,8]$. On the other hand, search engines are not optimised for health search queries $[2,3]$. Finding health information is a "trialand-error" process [14] due to the lack of suitable tools for health information retrieval, as well as human factors.

\section{A Possible Solution: Better Health Explorer}

We have identified the needs of health information seekers using observational studies and interviews [10, 11]. The findings lead to six design principles for exploratory health information seekers [12]. Further, we developed a prototype called Better Health Explorer $(\mathrm{BHX})$ to evaluate the design for exploratory seekers. Figure 1 shows a screenshot of the system.

$\mathrm{BHX}$ incorporates several design features for health 
information seekers. The left part of the screen looks similar to a normal web page, with summaries and outlines of articles added to aid the needs to previewing information. The exploration panel, on the right of the screen, includes coloured tiles as query results, sliders for refining queries, and checkboxes for filtering information by categories.

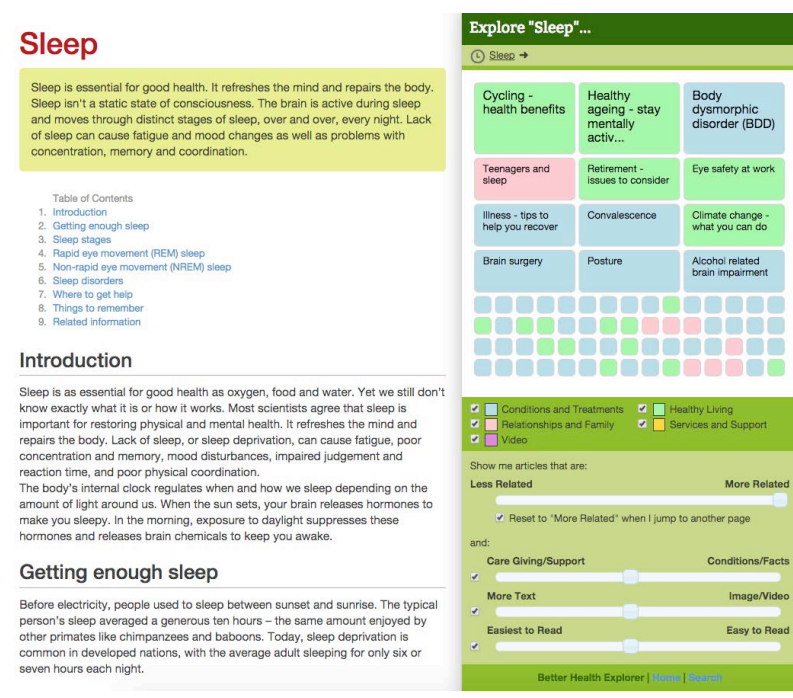

Figure 1. The user interface of Better Health Explorer.

The prototype is designed to support and encourage exploratory search. Users are exposed to a wide range of information that can be controlled by the sliders.

Each combination of slider settings equates to a unique query and the system shows the best results matching the preferences specified by the sliders. In this way, users can explore the information space without using keywords. Movements of the sliders animate the coloured tiles to illustrate the changes in the result list. Combinations of sliders add a measure of serendipity to the system, as useful articles unknown to the user beforehand may show up in the list. This playful experience helps engage users in the exploration process and encourages further reading.

\section{Research Design}

We used a mixed research approach to evaluate BHX. Participants were recruited to perform an observational study in a lab setting. They were given four tasks and used either a live health website (baseline) or BHX to find answers for the tasks. Both test websites contained the same content. Tasks were carried out in the order of a $4 \times 4$ Latin Square for counter-balancing learning and ordering effects [16]. The research was approved by the university's human ethics committee.

The four tasks consisted of two focused and two exploratory search tasks to enable comparison of the baseline website with BHX in both scenarios. The focused search tasks required participants to find information for caring for a close friend with a chronic disease, whereas the exploratory task asked them to find health topics that are interesting to themselves for conversations at a party. A think-aloud approach was adopted, and participants were required to fill a questionnaire after each task. Table 1 lists the surveyed questions. All questions were responded using 5-point Likert scales ranging from "strongly disagree" (1) to "strongly agree" (5).

\section{Results}

In this paper, we report on the preliminary results from 16 participants ( 9 male; 7 female). Their ages ranged from 20 to 72 (mean=35.1, SD=14.2). $12(75 \%)$ of them were university students; three (19\%) were staff; and one $(6 \%)$ was recruited externally. 


\begin{tabular}{|c|c|}
\hline No & Question \\
\hline Q2 & $\begin{array}{l}\text { I was uncertain about what } \\
\text { information to look for before } \\
\text { starting the task. }\end{array}$ \\
\hline Q3 & $\begin{array}{l}\text { The design (not the content) } \\
\text { of the website helped me to } \\
\text { figure out what information I } \\
\text { should look for. }\end{array}$ \\
\hline Q4 & $\begin{array}{l}\text { I learnt new knowledge } \\
\text { throughout the task. }\end{array}$ \\
\hline Q5 & $\begin{array}{l}\text { I was successful in getting the } \\
\text { information I needed. }\end{array}$ \\
\hline Q6 & $\begin{array}{l}\text { I found it easy to tell the } \\
\text { website what I needed. }\end{array}$ \\
\hline Q7 & $\begin{array}{l}\text { I was presented with diverse } \\
\text { information on the topic } \\
\text { through the design (not the } \\
\text { content) of the website. }\end{array}$ \\
\hline Q8 & $\begin{array}{l}\text { I was presented with topics } \\
\text { that I hadn't thought of before } \\
\text { but was interesting to me. }\end{array}$ \\
\hline Q9 & $\begin{array}{l}\text { I had enough time to look for } \\
\text { the information I needed. }\end{array}$ \\
\hline Q10 & $\begin{array}{l}\text { I found using the website } \\
\text { enjoyable. }\end{array}$ \\
\hline Q11 & $\begin{array}{l}\text { I felt engaged with the } \\
\text { website. }\end{array}$ \\
\hline Q12 & $\begin{array}{l}\text { I felt the website was easy for } \\
\text { me to use. }\end{array}$ \\
\hline Q13 & $\begin{array}{l}\text { I would use the website at } \\
\text { home if it were made } \\
\text { available. }\end{array}$ \\
\hline Q14 & $\begin{array}{l}\text { Overall, the website was } \\
\text { useful. }\end{array}$ \\
\hline Q15 & $\begin{array}{l}\text { Overall, I was satisfied with } \\
\text { the website. }\end{array}$ \\
\hline
\end{tabular}

Table 1. Post-questionnaire after each task.
Quantitative results are listed in Table 2. We applied Wilcoxon Test (using SPSS) to test the statistical significance between the baseline and $\mathrm{BHX}$ in each category of search tasks. Only mean values are shown due to space limitations.

\begin{tabular}{|c|r|r|r|r|r|l|}
\hline Q & $\begin{array}{c}\text { Baseline } \\
\text { Focused }\end{array}$ & $\begin{array}{c}\text { BHX } \\
\text { Focused }\end{array}$ & $\boldsymbol{p}$ & $\begin{array}{c}\text { Baseline } \\
\text { Explore }\end{array}$ & $\begin{array}{c}\text { BHX } \\
\text { Explore }\end{array}$ & $\boldsymbol{p}$ \\
\hline Q2 & 1.94 & 2.38 & & 3.69 & 3.50 & \\
\hline Q3 & 3.44 & 3.75 & & 3.25 & 4.00 & \\
\hline Q4 & 3.81 & 4.06 & & 3.63 & 4.19 & \\
\hline Q5 & 3.88 & 4.25 & & 3.75 & 3.94 & \\
\hline Q6 & 3.62 & 3.69 & & 2.75 & 3.56 & $*$ \\
\hline Q7 & 3.44 & 4.06 & $*$ & 3.69 & 4.44 & $*$ \\
\hline Q8 & 3.13 & 3.94 & $*$ & 3.63 & 4.31 & $*$ \\
\hline Q9 & 3.94 & 4.06 & & 3.75 & 3.81 & \\
\hline Q10 & 3.19 & 3.88 & $*$ & 3.38 & 4.06 & $*$ \\
\hline Q11 & 3.25 & 4.00 & $*$ & 3.69 & 4.13 & \\
\hline Q12 & 3.88 & 4.25 & & 3.81 & 4.06 & \\
\hline Q13 & 3.81 & 4.00 & & 3.63 & 4.19 & \\
\hline Q14 & 3.81 & 4.19 & & 3.75 & 4.50 & $*$ \\
\hline Q15 & 3.69 & 4.19 & $*$ & 3.75 & 4.31 & $*$ \\
\hline
\end{tabular}

Table 2. Evaluation result. Columns: Focused tasks - baseline vs. BHX; exploratory task - baseline vs. BHX; $p$ - statistical significance: $* p<0.05, \# p<0.01$.

\section{Discussion and Conclusion}

Firstly we analyse the responses about the design of tasks. Q2 shows that a similar level of task uncertainty is perceived by the participants in each group. The exploratory tasks were designed to have higher uncertainty and to be more open-ended [11, 15], and this was perceived by the participants. Q5 and Q9 display that the tasks were completed successfully within the time constraint. Among all tasks, new knowledge was learnt throughout the tasks in both systems (Q4)

Statistically, BHX outperformed the baseline website in providing diverse information (Q7) and stimulating serendipity $(\mathrm{Q} 8)$ in both task groups $(p<0.05)$. In the exploratory task, users felt that their information needs were easier to formulate in $\mathrm{BHX}(\mathrm{Q} 6, p<0.05)$, possibly due to the design of eliminating keyword searches. Also, Q10 and Q11 show that BHX brought an enjoyable experience $(p<0.05)$ and engagement $(p<0.05)$ for focused tasks into the information seeking process.

Though it is not statistically significant, BHX achieved a comparable degree of ease of use as the baseline health website (Q12). Q13 showed that participants would use it at home if possible. This supports the desirability of implementing a similar design.

Overall, participants reported the usefulness of $\mathrm{BHX}$ in exploratory tasks $(\mathrm{Q} 14, p<0.01)$ and the satisfactory of using $\mathrm{BHX}$ in both task group (Q15, $p<0.05)$. Further data analysis is needed to understand which factors were significant to support exploratory search, and which parts of the design result in a better experience of finding online health information.

To conclude, Better Health Explorer demonstrated positive results in the evaluation of supporting health information seekers. The preliminary quantitative results show that $\mathrm{BHX}$ outperformed a traditional health website in many aspects. A more detailed analysis with the collected qualitative data will strengthen this research. The final outcome will contribute to design guidelines for consumer health websites and a better model for supporting seekers' behaviour. 


\section{Acknowledgements}

We appreciate the support from the Department of Health and Human Services, Victorian State Government. Patrick Pang is supported by the Australian Federal and Victoria State Governments and the Australian Research Council through the ICT Centre of Excellence program, National ICT Australia (NICTA).

\section{References}

[1] Basil Alzougool, Shanton Chang, and Kathleen Gray. 2008. Towards a comprehensive understanding of health information needs. electronic Journal of Health Informatics 3, 2.

[2] Mike Benigeri, and Pierre Pluye. 2003. Shortcomings of health information on the Internet. Health Promotion International 18, 4: 381-386. http://dx.doi.org/10.1093/heapro/dag409

[3] Gretchen K. Berland, et al. 2001. Health information on the Internet: Accessibility, quality, and readability in English and Spanish. JAMA 285, 20: 2612-2621.

http://dx.doi.org/10.1001/jama.285.20.2612

[4] Donald O. Case. 2002. Looking for Information: A Survey of Research on Information Seeking, Needs, and Behaviour. Academic Press.

[5] Kristina Chapman, Charles Abraham, Valerie Jenkins, and Lesley Fallowfield. 2003. Lay

understanding of terms used in cancer consultations.

Psychooncology 12, 6: 557-566. http://dx.doi.org/10.1002/pon.673

[6] Susannah Fox, and Maeve Duggan. 2013. Health Online 2013. Pew Research Center's Internet \&

American Life Project. Retrieved November 14, 2014

from http://pewinternet.org/Reports/2013/Health online.aspx

[7] Alla Keselman, Allen C. Browne, and David R. Kaufman. 2008. Consumer health information seeking as hypothesis testing. J. Am. Med. Inform. Assoc 15, 4 484-495. http://dx.doi.org/10.1197/jamia.M2449

[8] Gang Luo, Chunqiang Tang, Hao Yang, and Xing Wei. 2008. MedSearch: a specialized search engine for medical information retrieval. Proceedings of the 17th ACM Conference on Information and Knowledge Management - CIKM '08.

http://dx.doi.org/10.1145/1458082.1458104

[9] Gary Marchionini. 2006. Exploratory search: from finding to understanding. Communications of the ACM 49, 4: 41. http://dx.doi.org/10.1145/1121949.1121979

[10] Patrick C.-I. Pang, Shanton Chang, Jon Pearce, and Karin Verspoor. 2014. Online health information seeking behaviour: understanding different search approaches. Proceedings of the 18th Pacific Asia Conference on Information Systems - PACIS 2014.

[11] Patrick C.-I. Pang, Karin Verspoor, Shanton Chang, and Jon Pearce. 2015. Conceptualising health information seeking behaviours and exploratory search: result of a qualitative study. Health and Technology 5 , 1: 45-55. http://dx.doi.org/10.1007/s12553-015-0096$\underline{0}$

[12] Patrick C.-I. Pang, Karin Verspoor, Jon Pearce, and Shanton Chang. 2015. Better Health Explorer: designing for health information seekers. Proceedings of the 27th Australian Conference on Human-Computer Interaction - OzCHI 2015.

[13] Amanda Spink, et al. 2004. A study of medical and health queries to web search engines. Health Information and Libraries Journal 21: 44-51. http://dx.doi.org/10.1111/j.1471-1842.2004.00481.x

[14] Elaine G. Toms, and Celeste Latter. 2007. How consumers search for health information. Health Informatics Journal 13, 3: 223-235.

http://dx.doi.org/10.1177/1460458207079901

[15] Ryen W. White, and Resa A. Roth. 2009.

Exploratory Search: Beyond the Query-Response Paradigm. Morgan and Claypool. 
http://dx.doi.org/10.2200/S00174ED1V01Y200901ICR $\underline{003}$

[16] E. J. Williams. 1949. Experimental designs

balanced for the estimation of residual effects of

treatments. Australian Journal of Scientific Research,

Series A: Physical Sciences 2: 149-168.

http://dx.doi.org/10.1071/CH9490149

[17] Tom D. Wilson. 1997. Information behaviour: an interdisciplinary perspective. Information Processing \&
Management 33, 4: 551-572.

http://dx.doi.org/10.1016/S0306-4573(97)00028-9

[18] Tom D. Wilson. 1999. Models in information

behaviour research. Journal of Documentation 55, 3: 249-270.

http://dx.doi.org/10.1108/EUM0000000007145

[19] Tom D. Wilson. 2006. Revisiting user studies and information needs. Journal of Documentation 62, 6: 680-684.

http://dx.doi.org/10.1108/00220410610714912 


\section{University Library}

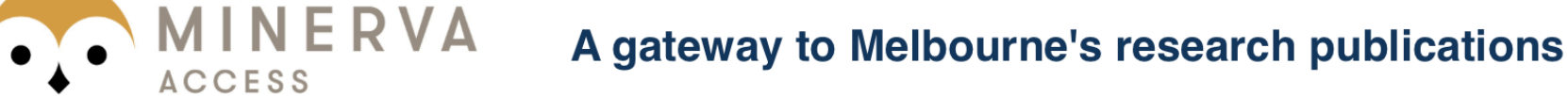

Minerva Access is the Institutional Repository of The University of Melbourne

Author/s:

Pang, PCI;Verspoor, K;Chang, S;Pearce, J

Title:

Better health information exploration

Date:

2015-12-07

Citation:

Pang, P. C. I., Verspoor, K., Chang, S. \& Pearce, J. (2015). Better health information exploration. Sari, E (Ed.) Duh, H (Ed.) Brereton, M (Ed.) T, JL (Ed.) Awori, K (Ed.) Wan Bt Ahmad, FW (Ed.) ACM International Conference Proceeding Series, 07-December-2015, pp.10-15. ACM. https://doi.org/10.1145/2846439.2846444.

Persistent Link:

http://hdl.handle.net/11343/274825 